\title{
Haemoptysis due to pulmonary venous stenosis
}

\author{
Silke Braun', Ivan Platzek², Klaus Zöphel³, Matthias Weise ${ }^{4}$, Martin Kolditz , \\ Michael Halank and Gert Hoeffken ${ }^{1}$
}

Affiliations: ${ }^{1}$ Medical Clinic I, Dept of Pneumology, University Hospital Carl Gustav Carus, Dresden, Germany. ${ }^{2}$ Dept of Radiology, University Hospital Carl Gustav Carus, Dresden, Germany. ${ }^{3}$ Dept of Nuclear Medicine, University Hospital Carl Gustav Carus, Dresden, Germany. ${ }^{4}$ Medical Clinic III, ZIM - Cardiology, University Hospital Carl Gustav Carus, Dresden, Germany.

Correspondence: S. Braun, Medical Clinic I, Dept of Pneumonology, University Hospital Carl Gustav Carus, Fetscherstr. 74, 01304 Dresden, Germany. E-mail: Silke.Braunduniklinikum-dresden.de

ABSTRACT Haemoptysis is a potentially life-threatening condition with the need for prompt diagnosis. In about $10-20 \%$ of all cases the bleeding source remains unexplained with the standard diagnostic approach. The aim of this article is to show the necessity of widening the diagnostic approach to haemoptysis with consideration of pulmonary venous stenosis as a possible cause of even severe haemoptysis and haemoptoe.

A review of the literature was performed using the Medline/PubMed database with the terms: "pulmonary venous stenosis", "pulmonary venous infarction" and "haemoptysis". Further references from the case reports were considered.

58 case reports and case collections about patients with haemoptysis due to pulmonary venous stenosis were detected. This review gives an overview about the case reports and discusses the underlying pathophysiology and the pros and cons of different imaging techniques for the detection of pulmonary venous stenosis.

Several conditions predispose to the obstruction of the mediastinal pulmonary veins. Clinical findings are unspecific and may be misleading. Pulmonary venous stenosis can be detected using several imaging techniques, yet three-dimensional magnetic resonance-angiography and three-dimensional contrastenhanced computed tomography are the most appropriate. Pulmonary venous stenosis should be considered in patients with haemoptysis.

○ @ERSpublications

Pulmonary venous stenosis should be considered in haemoptysis and is best diagnosed using CT or MRI venography http://ow.ly/tMPFP

\section{Introduction}

This article gives an overview about pulmonary venous stenosis as a possible cause of haemoptysis. Inflammatory and malignant pulmonary diseases may cause haemoptysis, and diagnostic algorithms as management principles for haemoptysis are well described. However, with the standard diagnostic approach, including bronchoscopy, computed tomography (CT) and bronchial angiography, in about $10-20 \%$ of cases the bleeding source remains unexplained [1]. Although many cases were reported of patients with severe haemoptysis due to pulmonary venous obstruction [2-59] (online supplementary table S1), the pulmonary veins are only infrequently mentioned in the literature about the management of

This article has supplementary material available from err.ersjournals.com

Received: May 192013 | Accepted after revision: Sept 062013

Conflict of interest: None declared.

Provenance: Submitted article, peer reviewed.

Copyright CERS 2014. ERR articles are open access and distributed under the terms of the Creative Commons Attribution Non-Commercial Licence 4.0. 
haemoptysis [60-65]. Besides the rare condition of congenital pulmonary venous stenosis, there are several clinical conditions predisposing to the obstruction of the central pulmonary veins, like mediastinal masses such as solid neoplasms or bulky lymphoma, fibrosing mediastinitis and mediastinal granulomatous diseases. In addition, lung transplantation [66, 67] and lobectomy or bilobectomy [24] may result in pulmonary venous stenosis (table 1). Furthermore, cor triatriatum [53], left atrial myxoma and postpneumonectomy syndrome may cause functional pulmonary venous stenosis. Since the interventional ablation strategies for atrial fibrillation target the veno-atrial junctions of the pulmonary veins, plenty of cases with haemoptysis due to post-procedural pulmonary vein stenosis were reported. Due to thermal injury at the veno-atrial junctions [68, 69], pulmonary venous stenosis has become a well-recognised complication of these ablation procedures, with sometimes even fatal peri-procedural haemoptoe [41]. Because of this potentially life-threatening complication, ablation technology has changed from the intraostial radiofrequency ablation technique to the antral cryoballoon isolation technique during the past decade. With the radiofrequency procedures, pulmonary vein stenosis rates of up to $30-40 \%$ in scheduled surveillances were reported. With the cryoballoon technique, the official pulmonary vein stenosis rate is about 1-3\% [70]. In the USA alone, about 40000-50000 atrial fibrillation ablation procedures are performed each year. This review focuses on haemoptysis due to the obstruction of the central mediastinal pulmonary veins.

\section{Anatomy of the mediastinal pulmonary veins}

The embryological formation of the pulmonary veins is quite complex and there is a remarkable diversity of pulmonary vein connections into the left atrium [71-74]. The classical description of two left-sided (left superior (LSPV) and left inferior (LIPV)) and two right-sided (right superior (RSPV) and right inferior (RIPV)) separately ending pulmonary veins accounts for only $\sim 70 \%$ of the normal population. Approximately $28 \%$ of people have three to five ostia at the right side and $14 \%$ of the population have a single ostium at the left side. At the right side an accessory right pulmonary vein is common. The rightsided middle lobe vein (RMLV) may drain via the superior pulmonary vein, the inferior pulmonary vein or separately. The variant of RMLV drainage via the RIPV may result in life-threatening post-operative haemoptysis and respiratory distress in case of right lower lobectomy. Therefore, careful pre-operative assessment of the pulmonary venous return is crucial in patients undergoing pulmonary surgery $[24,75,76]$. In addition to congenital stenosis of pulmonary veins with normal connection, the varying forms of partial anomalous venous return may be combined with a pulmonary venous stenosis.

\section{Pathophysiology}

To understand the pathophysiology of haemoptysis in cases of pulmonary venous stenosis, it is important to know that both the pulmonary and the bronchial circulation drain via the pulmonary veins into the left atrium. Thus, in pulmonary venous stenosis the drainage systems of both lung circulations are blocked. Typical consequences include distended pleural-hilar bronchial veins, alveolar haemorrhage, a friable endobronchial mucosa, a reduced lymphatic drainage, interstitial pulmonary oedema, enlarged hilar lymph nodes, enlarged lymph vessels and sometimes pleural effusions [77-82]. To keep the lung an optimal

TABLE 1 Factors causing morphological or functional pulmonary venous stenosis

\section{Congenital pulmonary venous stenosis}

Circumscript pulmonary venous stenosis at the veno-atrial junctions of one or more pulmonary veins

Congenital hypoplasia of one or more pulmonary veins

Partial anomalous venous connection with stenosis of the aberrant veins

Cor triatriatum

\section{Acquired pulmonary vein stenosis}

Mediastinal or pulmonary neoplasms resulting in extrinsic compression of the pulmonary veins in their run through the mediastinum

Fibrosing mediastinitis due to mediastinal granulomatous diseases

Circumscript pulmonary venous stenosis as a complication of catheter-guided therapy for atrial fibrillation Post-operative pulmonary vein thrombosis after lung transplantation

Right-sided lower lobectomy in case of drainage of the right middle lobe vein into the right inferior pulmonary vein with subsequent right middle lobe venous occlusion

Intraluminal growth of neoplasms in the pulmonary veins or in the left atrium

Post-operative stenosis after surgical correction of partial or total anomalous venous return

Restenosis or stent-thrombosis after interventional dilatation of pulmonary venous-stenosis

Functional pulmonary venous stenosis

Post-pneumonectomy syndrome after right-sided pneumonectomy with compression of the left pulmonary veins between the aorta and left ventricle in case of a cardiac shift into the right hemithorax 


\section{TABLE 2 Histological changes in pulmonary venous stenosis}

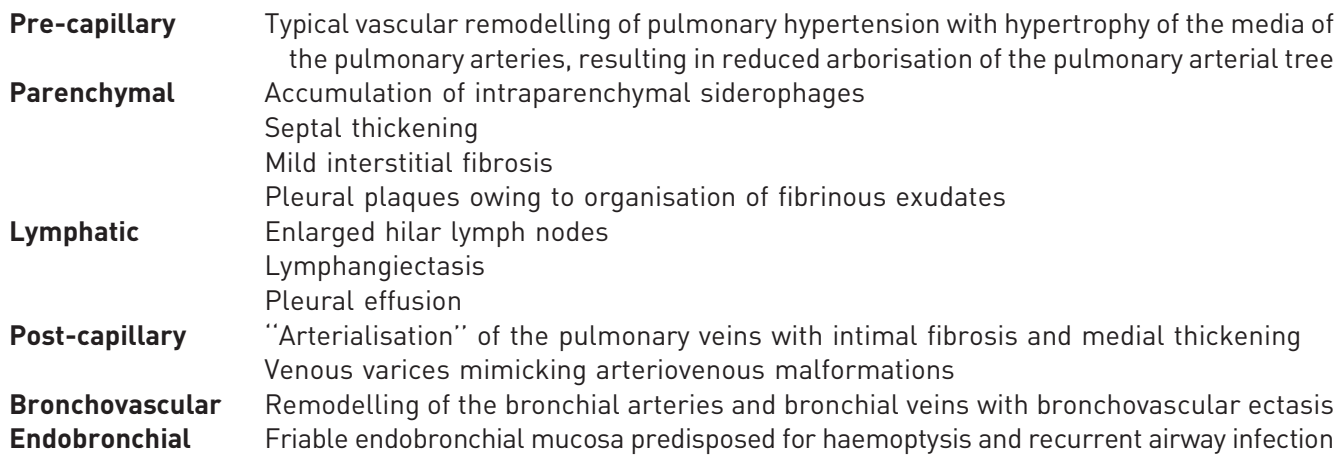

gas-exchanging system, the pulmonary arterial blood flow is also affected, with redistribution of the pulmonary arterial blood flow towards regions with lower vascular resistance [83-87]. In severe stenosis even a reversal flow in the pulmonary arteries with development of pulmonary venous hypertension, pulmonary arterial remodelling and a decreased arborisation of the pulmonary arterial tree may develop $[88,89]$ (table 2).

\section{Haemoptysis and other clinical symptoms and signs caused by pulmonary venous stenosis}

Depending on the acuity of the pulmonary venous obstruction and the development of venous collaterals the venous parenchymal and mucosal bleeding may vary from even asymptomatic courses with occult alveolar haemorrhage to acute fatal haemoptoe. In cases of haemoptysis due to pulmonary venous stenosis the expectorated blood is deoxygenated and, therefore, usually darker compared to haemoptysis with offspring of the systemic bronchial arteries. As in other cases with massive haemoptysis, clinical management includes early endotracheal intubation with large-bore tubes in an intensive care unit setting, early bronchoscopy for localisation of the bleeding side and early endobronchial therapy to protect the nonbleeding side. The endobronchial changes with dilatation of the dense submucosal venous plexus can often be seen in bronchoscopy and the alveolar haemorrhage will result in a bloody bronchoalveolar lavage or, if occult, in an increased number of siderophages in the cell differentiation [82]. Due to the dense network between the pulmonary and bronchial circulation, extensive collaterals between both circulations may develop, with the possible occurrence of secondary bronchial and pulmonary venous varices in the long run. Misinterpretation of these varices and collaterals as pulmonary arteriovenous malformations has been reported. Bronchial artery embolisation may be deleterious in cases of hindered pulmonary venous drainage.

Besides haemoptysis, the typical clinical symptoms of pulmonary venous stenosis are tussive irritation, exertional dyspnoea, recurrent pulmonary infections and signs of pulmonary venous hypertension. Mimicking of primarily pulmonary diseases, such as recurrent pneumonia, interstitial pneumonitis, lung cancer and pulmonary embolism, has been reported in animal studies, as in many case reports [19, 90-93]. Mild interstitial fibrosis is thought to originate from the organisation of haemorrhagic oedema in the alveolar walls. The resulting clinical signs of pulmonary venous stenosis are highly unspecific and may, therefore, be misleading. Unilateral pleural effusions, haemoptysis in combination with enlarged hilar lymph nodes and pulmonary infiltrates in combination with positive blood cultures are only a few examples of the consequences of pulmonary venous stenosis. Figure 1 demonstrates different clinical signs caused by pulmonary venous stenosis in a patient with life-threatening haemoptysis. Haemoptysis in combination with the history of mediastinal masses, granulomatous diseases, interventional procedures for atrial fibrillation therapy, lobectomy or right-sided pneumonectomy, pulmonary hypertension, recurrent respiratory infections or after lung transplantation should prompt the suspicion of pulmonary venous stenosis (table 1). Yet the diagnostic workup of pulmonary venous stenosis is elusive, which is why the different diagnostic procedures to detect pulmonary venous stenosis are discussed here.

\section{Diagnostic imaging}

Accurate imaging of the anatomical and functional properties of the pulmonary veins is challenging. For example, a pathologic perfusion scan in combination with haemoptysis may be misinterpreted as acute pulmonary embolism $[94,95]$. Various imaging techniques have been investigated to explore the mediastinal pulmonary veins, such as transoesophageal echocardiography (TOE), ventilation/perfusion scan, 

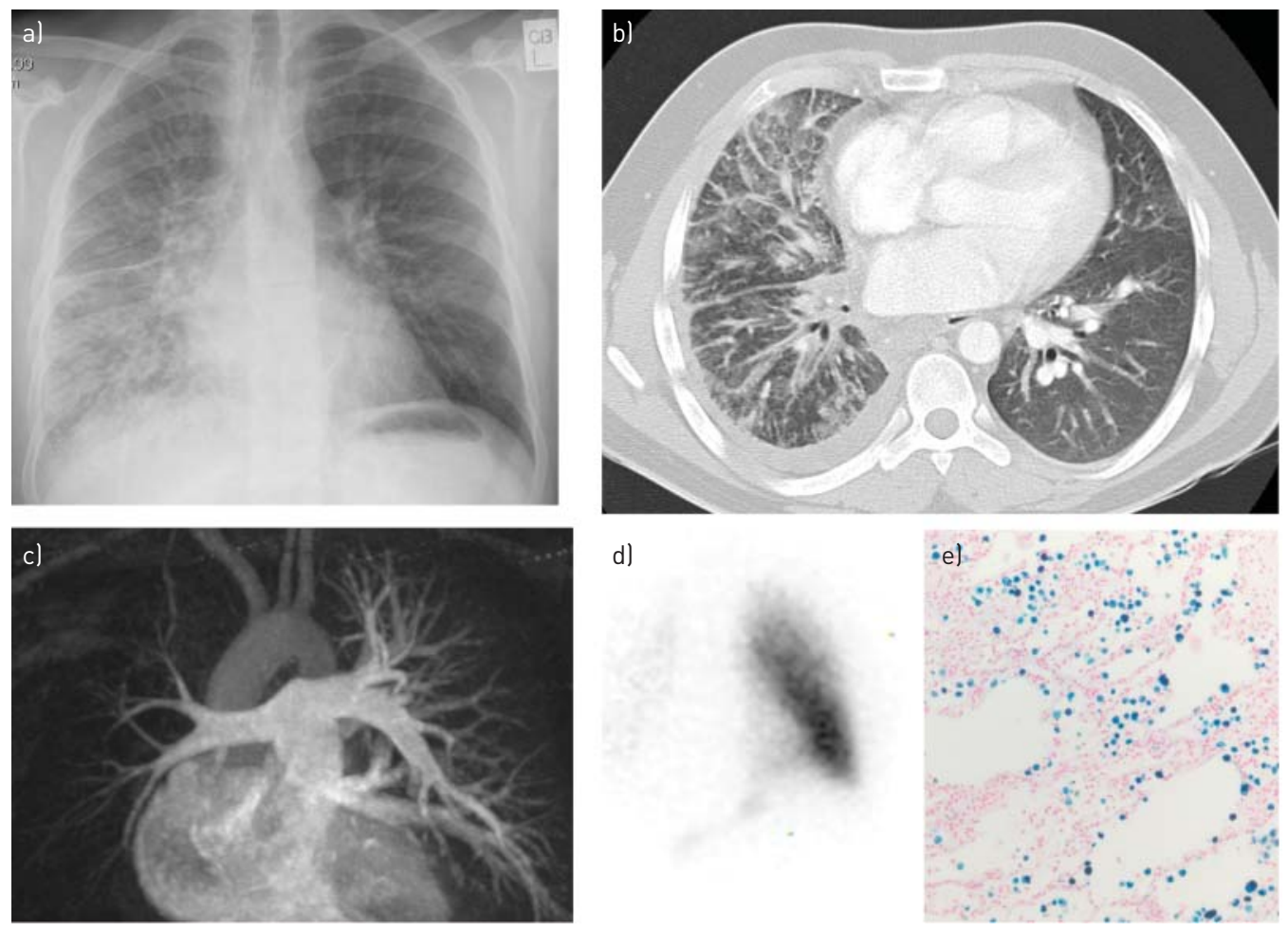

FIGURE 1 a) Chest radiograph, b) multislice computed tomography angiography, c) three-dimensional magnetic resonance angiography, d) perfusion scintigraphy and e) iron staining of a lung biopsy of a patient with severe haemoptysis due to occlusion of the right-sided pulmonary veins. Note the right-sided interstitial infiltrates, the hilar lymphadenopathy, the pleural effusion, the perfusion shift to the left lung and the siderophages in the specimen (a-e, respectively).

contrast-enhanced multisclice CT, magnetic resonance angiography and direct pulmonary venography. WOOD et al. [96] compared CT, TOE and direct pulmonary venography to assess the number of detectable pulmonary veins and their diameters at the veno-atrial junctions in 24 patients. In contrast to CT, which detected 98 pulmonary veins, TOE detected only 80 and direct venography detected only 71 pulmonary veins. Thus, direct angiography missed $27 \%$ and TOE missed $18 \%$ of the pulmonary veins. With TOE in particular, the inferior and the right middle lobe veins will be missed. Depending on which imaging technique is used, the ostial diameters vary significantly from $1.6 \pm 0.3 \mathrm{~cm}$ using direct venography to $1.1 \pm 0.25 \mathrm{~cm}$ using TOE. Therefore, neither TOE nor direct pulmonary venography can be recommended for the exclusion of pulmonary venous stenosis. Depending on which imaging technique is used, the ostial diameters vary significantly from $1.6 \pm 0.3 \mathrm{~cm}$ using direct venography to $1.1 \pm 0.25 \mathrm{~cm}$ using TOE.

A brief discussion of the pros and cons of these imaging techniques referring to pulmonary venous stenosis is shown in table 3 and discussed below.

\section{Ventilation/perfusion scan}

The ventilation/perfusion scan usually is performed for the detection of pulmonary embolism, but is also reported to serve as an effective screening tool for the detection of haemodynamically relevant pulmonary venous stenosis [84-87]. To maintain the lung, an optimal gas exchanging system, backward transmission of elevated venous pressures will immediately induce a local increase of vascular resistance with a subsequent shift of the pulmonary arterial blood flow towards regions with lower resistance. This shift explains the perfusion deficits in lung perfusion scans of patients with haemodynamically relevant pulmonary venous stenosis. LEPADAT et al. [87] demonstrated an immediate shift of the pulmonary perfusion after pulmonary arterial as well as pulmonary venous ligation. NANTHAKUMAR et al. [84] demonstrated pathological perfusion scans with a resting pressure gradient $>5 \mathrm{mmHg}$ between the pulmonary vein and the left atrium, or with $a \geqslant 80 \%$ luminal stenosis. To minimise false-positive pulmonary embolism results, lung perfusion scans are best performed using the technique of single photon emission computed tomography (SPECT) and should be interpreted in conjunction with the corresponding ventilation scan. However, in case of alveolar haemorrhage and endobronchial thrombus formation, 
TABLE 3 Comparison of different imaging techniques for the detection of pulmonary venous stenosis

Imaging techniques Pros Cons

\section{Perfusion scintigraphy}

Transoesophageal echocardiography

3D-MRA venography

3D-CT venography

Direct venography
Perfusion deficits likely in pressure gradients left atrium/pulmonary vein $>5 \mathrm{mmHg}$ and/or $>80 \%$ stenosis

Information about left and right heart function

Consider relevant stenosis if:

pulmonary vein flow velocity $>100 \mathrm{~cm} \cdot \mathrm{s}^{-1}$

pulmonary vein diameter $<5 \mathrm{~mm}$

Simultaneous visualisation of: mediastinal structures

left and right heart function

partial anomalous venous return

Flow quantification with phase contrast

Data acquisition within a few seconds

Simultaneous visualisation of: pulmonary parenchyma mediastinal structures left and right heart

Post-processing possible in all planes

Can be used in combination with therapeutic interventions

Retrograde pulmonary vein detection in

near-total occlusion

Assessment pressure gradient from pulmonary vein pressure to left atrium pressure
Low specificity, perfusion deficits in cases with pulmonary embolism

Inferior pulmonary vein difficult to visualise Anomalies like accessory pulmonary veins, common left trunk or hypoplasia are often missed

Underestimates pulmonary vein diameter Limited post-processing

Limited visualisation of the pulmonary parenchyma

lodine contrast media and radiation exposure

Most invasive

Lowest sensitivity for the detection of pulmonary veins in comparison with the other techniques

Overestimates diameter of pulmonary veins

Restricted to luminography

3D: three-dimensional; MRA: magnetic resonance angiography; CT: computed tomography.

pulmonary venous stenosis may also result in a combined ventilation/perfusion deficit. Perfusion deficits may be missed if the stenosis is $<50 \%$.

\section{Magnetic resonance imaging}

Magnetic resonance imaging (MRI) offers multiple advantages such as noninvasiveness, freedom from radiation exposure and visualisation of the circumadjacent mediastinal structures. Furthermore, it provides information about blood flow and left and right ventricular function. For the assessment of pulmonary venous stenosis different MRI techniques are available, such as noncontrast white-blood imaging, threedimensional (3D) steady-state free precession magnetic resonance angiography, four-dimensional flow MRI, phase-contrast velocity mapping and contrast-enhanced gadolinium magnetic resonance angiography [88, 89, 97-101]. Magnetic resonance-perfusion imaging has $95 \%$ sensitivity and $100 \%$ specificity to detect perfusion deficits in cases of haemodynamically relevant pulmonary venous stenosis, compared to the scintigraphic SPECT technique [97]. With phase-contrast MRI, the pulmonary venous flow and mean flow velocities in the mediastinal veins can be quantified. Signs of venous obstruction include flow acceleration downstream from the stenotic lesion and a loss of the normal phasic changes. Normal systolic and diastolic peaks of the pulmonary venous blood flow were reported at $51 \pm 16 \mathrm{~cm} \cdot \mathrm{s}^{-1}$ and $47 \pm 11 \mathrm{~cm} \cdot \mathrm{s}^{-1}$. There is a significant variability in pulmonary vein diameter and cross-sectional area over the cardiac cycle, with greatest diameters in ventricular diastole and a mean difference in diameter of $\sim 15 \%$ and $27 \%$ for the crosssectional area. For optimal imaging of the pulmonary veins, the authors suggest a gadolinium-enhanced, bolus-tracking technique with the region of interest in the left atrium to match the imaging sequences with the maximum contrast media peak into the left atrium.

\section{Computed tomography}

The advantage of multislice CT-venography compared to MRI is the simultaneous visualisation of the pulmonary parenchyma and that 3D-reconstructions of the pulmonary veins can easily be performed. CT scanning provides additional information about the functional consequences of pulmonary venous stenosis, because the morphological parenchymal alterations, such as thickening of the septal walls, mosaic pattern 
due to inhomogeneous aeration and perfusion, may not be detected with MRI. As with MRI, the scanning delay time should be defined by a bolus-tracking technique focusing the bolus arrival into the left atrium for optimal visualisation of the veno-atrial junctions. Mean pulmonary vein diameters were reported as follows: RSPV 13-15 mm, LSPV 16-17 mm, RIPV 16-17 mm, LIPV 14-15 mm and middle lobe vein 8.2-8.9 mm. Up-to-date (64-row or 128-row) multislice-detector CT scans are able to visualise the veno-atrial junctions with excellent spatial resolution [102-107].

\section{Echocardiography}

The transthoracic echo window usually is unsatisfactory for the evaluation of the pulmonary venous flow in adults. TOE, with the use of colour- and Doppler-mode at a Nyquist limit of $\sim 40 \mathrm{~cm} \cdot \mathrm{s}^{-1}$, offers a much better ultrasound window. For the pulsed-wave Doppler analysis the standard position of the sample volume is about $1-2 \mathrm{~cm}$ upstream from the pulmonary vein orifices, where normally a triphasic flow pattern can be delineated. This flow profile is hooked to the left atrial pressure with mean velocities of $\sim 0.5 \mathrm{~m} \cdot \mathrm{s}^{-1}$ in systole and $0.4 \mathrm{~m} \cdot \mathrm{s}^{-1}$ in diastole [108]. Pulmonary venous stenosis is suspected if peak flow velocities exceeds $1.0 \mathrm{~m} \cdot \mathrm{s}^{-1}$ and/or if pulmonary vein diameter is $<5 \mathrm{~mm}$. The inferior pulmonary veins and accessory right pulmonary veins are often difficult to view because Doppler imaging is highly angle dependent. Visualisation of the pulmonary veins with TOE is much poorer compared to the newer generations of multislice imaging techniques [96].

\section{Direct venography}

Direct venography is the most invasive and time-consuming method and is restricted to a planar luminography. Furthermore, a trans-septal puncture is required. However, in the case of a near-total pulmonary vein occlusion, a flow-through pulmonary angiogram sometimes demonstrates a residual pulmonary vein lumen, which then facilitates a retrograde recanalisation of the pulmonary vein [10]. Except in the case of a near-total occlusion, the multislice techniques have a much higher diagnostic accuracy, which is why the direct pulmonary venous angiography is performed in the context of therapeutic procedures rather than for diagnostic reasons.

\section{Therapeutic options to restore pulmonary venous drainage in the case of central pulmonary venous stenosis}

If pulmonary venous stenosis is diagnosed, catheter-guided and surgical procedures are established for therapy, depending on the aetiology of the stenosis. Pulmonary venous stenosis is usually a progressive disease resulting in a kind of functional lobectomy due to the perfusion shift, which is why symptomatic higher stenosis should be treated. In the case of pulmonary venous stenosis at the veno-atrial junctions due to interventional therapy of atrial fibrillation, a percutaneous catheter-guided dilatation is recommended. After puncture of the vena femoralis using the Seldinger technique and subsequent atrial transseptal

TABLE 4 Diagnostic approach to haemoptysis and therapeutic options to restore the pulmonary venous drainage

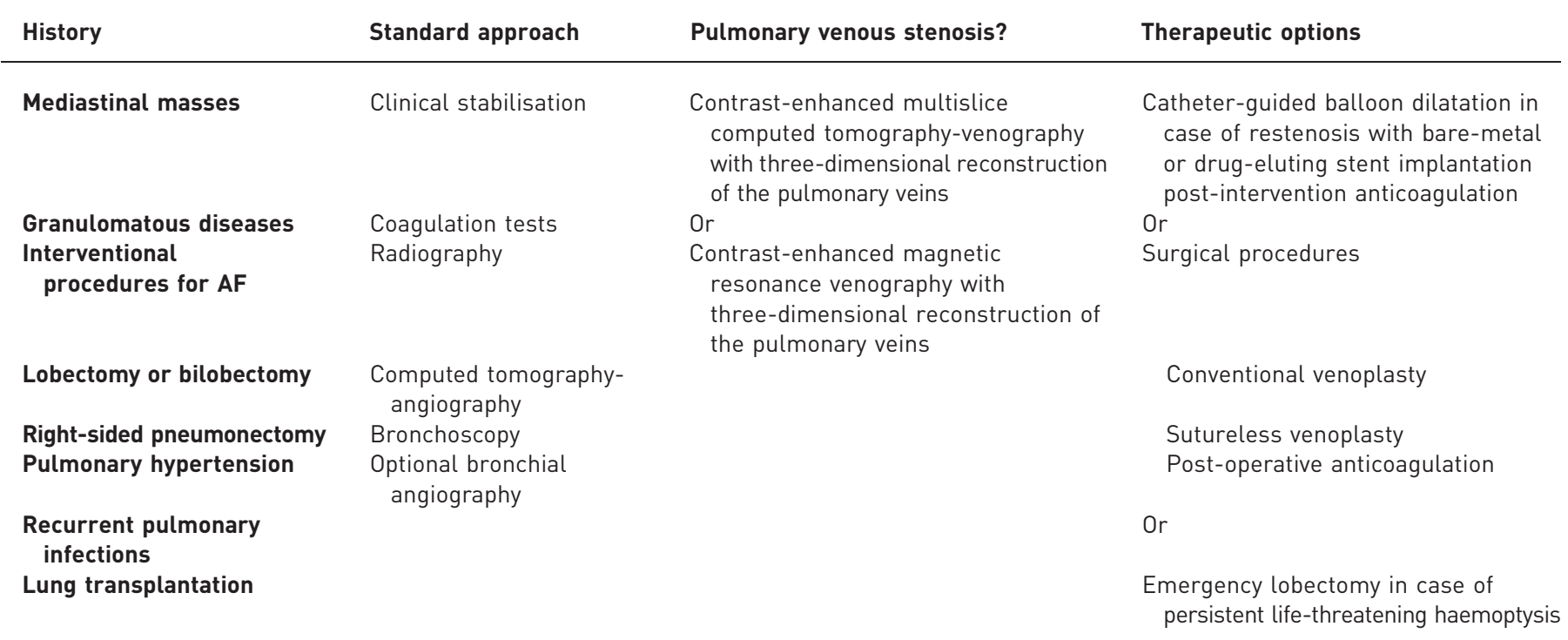


puncture, a guiding catheter is placed in the left atrium under fluoroscopy. Then, the interventionalist places a guidewire into the stenosed pulmonary vein and dilates the venous stenosis with a balloon catheter. Surgical procedures are commonly used in cases of congenital stenosis of the veno-atrial junctions either with conventional or with sutureless venoplasty or a pericardial patchplasty [109]. For aquired pulmonary venous stenosis due to mediastinal masses, the therapeutic decision is usually made subject to individual aspects. Both surgical techniques, as with catheter-guided techniques, have the problem of an extremely high proportion (up to 50\%) of restenosis. Catheter-guided stent implantation with bare-metal stents or drug-eluting stents may be an alternative if restenosis develops [110]. If massive bleeding persists, an urgent surgical lobectomy or pneumonectomy can be life saving. Anticoagulation is mandatory after successful recanalisation of pulmonary venous stenosis; however, in the acute setting with haemoptysis anticoagulation may be detrimental. Table 4 suggests a diagnostic algorithm for patients with unexplained haemoptysis, to exclude pulmonary venous stenosis of the mediastinal pulmonary veins and the veno-atrial junctions, and it describes the therapeutic options to restore the pulmonary venous drainage.

\section{Conclusions}

Pulmonary venous stenosis should be considered in the differential diagnosis of patients with haemoptysis. In particular, patients with a history of mediastinal masses, interventional therapy for atrial fibrillation or right lower lobectomy are predisposed to pulmonary venous obstruction. TOE, ventilation/perfusion scans and direct venoography may detect pulmonary venous stenosis, but cannot be recommended for the exclusion of pulmonary venous stenosis. Gadolinium-enhanced magnetic resonance venography and contrast-enhanced multislice CT with 3D reconstruction of the veno-atrial junctions are the most appropriate methods for the detection of pulmonary venous stenosis. For optimal visualisation of the venoatrial junctions, the correct scanning delay time is important.

\section{References}

1 Herth F, Ernst A, Becker H. Long-term outcome and lung cancer incidence in patients with hemoptysis of unknown origin. Chest 2001; 120: 1592-1594.

2 Calero Acuña C, Elías Hernández T. Haemoptysis as a first sign of pulmonary venous stenosis secondary to radiofrequency ablation of atrial fibrillation. Arch Bronchopneumol 2011; 47: 162-163.

3 Aguilar-Cabello M, Martín-Bermúdez R, Jiménez-Jiménez J, et al. Hemoptisis amenazante y estenosis de venas pulmonares tras ablación por fibrilación auricular [Threatening hemoptysis and pulmonary vein stenosis after ablation due to atrial fibrillation]. Med Intensiva 2012; 36: 56-72.

4 Alexander G, Reddi A, Reddy D. Idiopathic pulmonary vein thrombosis: a rare cause of massive hemoptysis. Ann Thorac Surg 2009; 88: 281-283.

5 Beerman LB, Oh K, Park SC, et al. Unilateral pulmonary vein atresia: clinical and radiographic spectrum. Pediatr Cardiol 1983; 4: 105-112.

6 Berry DF, Buccigrossi D, Peabody J, et al. Pulmonary vascular occlusion and fibrosing mediastinitis. Chest 1986; 89: 296-301.

7 Bhagwandien R, Van Belle Y, de Groot N, et al. Hemoptysis after pulmonary vein isolation with a cryoballon: an analysis of the potential etiology. J Cardiovasc Electrophysiol 2011; 22: 1067-1069.

8 Botticelli J, Schlueter D, Lange R. Pulmonary venous and arterial hypertension due to chronic fibrous mediastinitis. Circulation 1966; 33: 862-871.

9 Braun S, Platzek I, Kolditz M, et al. Belastungsdyspnoe, Husten und Hämoptysen mit pathologischer Perfusionsszintigraphie [Dyspnea, cough and hemoptysis with pathologic perfusion scintigraphy]. Pneumologe 2012; 9: 465-469.

10 Braun S, Kolditz M, Halank M, et al. Hämoptysen infolge Pulmonalvenenstenose und -verschluss nach Pulmonalvenen-Isolation bei Vorhofflimmern [Hemoptysis because of pulmonary vein stenosis and occlusion after pulmonary vein isolation for atrial fibrillation]. Dtsch Med Wochenschr 2011; 136: 626-630.

11 Burri E, Duwe J, Kull C, et al. Pulmonary vein thrombosis after lower lobectomy of the left lung. J Cardiovasc Surg 2006; 47: 609-612.

12 Cabrera A, Vazquez C, Lekuona I. Isolated atresia of the left pulmonary veins. Int J Cardiol 1985; 7: 298-302.

13 Cho YK, Kim YO, Choi WY, et al. Bilateral congenital pulmonary vein stenosis with a normal connection. J Cardiovasc Ultrasound 2008; 16: 54-58.

14 Conte G, Gian-Battista C, Casado-Arroyo R, et al. Pulmonary vein intramural hematoma as a complication of cryoballoon ablation of paroxysmal atrial fibrillation. J Cardiovasc Electrophysiol 2013; 24: 930-931.

15 Cullen S, Deasy PF, Tempany E, et al. Isolated pulmonary vein atresia. Br Heart J 1990; 63: 350-354.

16 den Bakker M, Thomeer M, Maat A, et al. Life-threatening hemoptysis caused by chronic idiopathic pulmonary hilar fibrosis with unilateral pulmonary vein occlusion. Ann Diagn Pathol 2005; 9: 319-322.

17 Di Biase L, Fahmy TS, Wazni OM, et al. Pulmonary vein total occlusion following catheter ablation for atrial fibrillation. J Am Coll Cardiol 2006; 48: 2493-2499.

18 Dupuis C, Remy J, Remy-Jardin M, et al. Le syndrome du cimeterre avec absence anatomique ou fonctionnelle de l'artère pulmonaire droite. À propos de quatre observations [Scimitar syndrome with anatomical or functional absence of the right pulmonary artery. Apropos of 4 cases]. Arch Pediatr 1995; 2: 347-352.

19 Ernst S, Ouyang F, Goya M, et al. Total pulmonary vein occlusion as a consequence of catheter ablation for atrial fibrillation mimicking primary lung disease. J Cardiovasc Electrophysiol 2003; 14: 366-370.

20 Guzzi M, Bouza G, Rodríguez R, et al. Estenosis de vanos pulmonares post ablaction por radiofrecuencia [Pulmonary vein stenosis after radio frequency ablation]. Medicina (B Aires) 2011; 71: 251-253. 
21 Harrison JK, Hearne SE, Baker SE, et al. Esophageal varices in association with unilateral pulmonary vein atresia. Cathet Cardiovasc Diagn 1996; 38: 387-392.

22 Heyneman L, Nolan R, Harrison K, et al. Congenital unilateral pulmonary vein atresia: radiologic findings in three adult patients. AJR Am J Roentgenol 2001; 177: 681-685.

23 Holmes D, Monahan K, Packer D. Pulmonary vein stenosis complicating ablation for atrial fibrillation: clinical spectrum and interventional considerations. JACC Cardiovasc Interv 2009; 2: 267-276.

24 Hovaguimian H, Morris J, Gately H, et al. Pulmonary vein thrombosis following bilobectomy. Chest 1991; 99: 1515-1516.

25 Hull J, Menzies-Gow A, Nicholson A, et al. Exercise-induced haemoptyis: a thoroughbred cause? Thorax 2013; 68: 599-600.

26 Jaitovich A, Harmath C, Cuttica M. Pulmonary vein stenosis and hemoptysis. Am J Respir Crit Care Med 2012; 185: 1023.

27 Jones R, Dawson A, Jenkins GH, et al. Sarcoidosis-related pulmonary veno-occlusive disease presenting with recurrent haemoptysis. Eur Respir J 2009; 34: 517-520.

28 Karlsson SE, Kidron P. Radiofrekvensablation av formaksflimmer inducerade lungvensstenos. Ett fall visar ny orsak till hemoptys [Radiofrequency ablation for atrial fibrillation induced pulmonary vein stenosis. A case shows new cause of hemoptysis]. Lakartidningen 2008; 105: 998-999.

29 Kojodjojo P, Wong T, Wright AR, et al. Pulmonary venous stenosis after treatment for atrial fibrillation. BMJ 2008; 336: 830-832.

30 Kovach A, Cheng G, Channick C, et al. Postradiofrequency ablation inflammatory pseudotumor associated with pulmonary venoocclusive disease: case report and review of the literature. Ann Diagn Pathol 2013; 17: 466-469.

31 Laboux L, Michaud JL, Cornet E. Atresie unilateral des veins pulmonaires. Signes cliniques, hemodynamiques et angiographiques a propos d'une observation [Unilateral atresia of the pulmonary veins. Clinical, hemodynamic and angiographic signs apropos of a case]. Arch Mal Coeur Vaiss 1972; 65: 1155-1158.

32 Lange T, Luchner A, Endemann D, et al. A 46-year-old man with dyspnea and hemoptysis 3 years following mitral valve repair. Chest 2007; 132: 704-707.

33 Lee HN, Kim YT, Cho S. Individual pulmonary vein atresia in adults: report of two cases. Korean J Radiol 2011; 12: 395-399.

34 Lee J, Lee J, Kang C, et al. Unilateral pulmonary vein stenosis with life-threatening hemoptysis: a case report. Korean J Thorac Cardiovasc Surg 2005; 38: 725-728.

35 Loyd JE, Tillma B, Atkinson JB, et al. Mediastinal fibrosis complicating histoplasmosis. Medicine 1988; 67: 295-310

36 Matsuyama K, Matsumoto M, Ogino $\mathrm{H}$, et al. Pulmonary venous obstruction requiring lobectomy for hemoptysis after a Glenn operation. Jpn J Thorac Cardiovasc Surg 2001; 49: 629-631.

37 Mendelson E, Mintzer R, Hidvegi D. Venoocclusive pulmonary infarct: an unusual complication of fibrosing mediastinitis. AJR Am J Roentgenol 1983; 141: 175-176.

38 Morcos KH, Roditi G, Craig S. Life-threatening haemoptysis due to tracheal varices secondary to pulmonary vein obstruction. Thorax 2013; 68: 894-895.

39 Artero Muñoz I, Serrano Puche F, Padín Marín MI, et al. Atresia congénita unilateral de las venas pulmonares: hallazgos radiológicos [Congenital unilateral pulmonary vein atresia: imaging findings]. Radiologia 2008; 50: 82-85.

40 Nehra D, Liberman M, Vagefi PA, et al. Complete pulmonary venous occlusion after radiofrequency ablation for atrial fibrillation. Ann Thorac Surg 2009; 87: 292-295.

41 Nilsson B, Chen X, Pehrson S, et al. Acute fatal pulmonary vein occlusion after catheter ablation of atrial fibrillation. J Interv Card Electrophysiol 2004; 11: 127-130.

42 Otto D, von Falkenhausen U, Schellong S, et al. Unilaterale Pulmonalveneratresie im fruhen Erwachsenenalter [Unilateral pulmonary vein atresia in early adulthood]. Pneumologie 1998; 52: 135-139.

43 Packer DL, Keelan P, Munger TM, et al. Clinical presentation, investigation, and management of pulmonary vein stenosis complicating ablation for atrial fibrillation. Circulation 2005; 111: 546-554.

44 Patel N, Petterson G, Murat Tuzcu E, et al. Sucessful surgical repair of iatrogenic pulmonary vein stenosis. J Cardiovasc Electrophysiol 2012; 23: 656-658.

45 Prieto L, Schoenhagen P, Arruda M, et al. Comparison of stent versus balloon angioplasty for pulmonary vein stenosis complicating pulmonary vein isolation. J Cardiovasc Electrophysiol, 19: 673-678.

46 Pürerfellner $\mathrm{H}$, Aichinger J, Martinek $\mathrm{M}$, et al. Incidence, management, and outcome in significant pulmonary vein stenosis complicating ablation for atrial fibrillation. Am J Cardiol 2004; 93: 1428-1431.

47 Qureshi AM, Prieto LR, Latson LA, et al. Transcatheter angioplasty for acquired pulmonary vein stenosis after radiofrequency ablation. Circulation 2003; 108: 1336-1342.

48 Ravenel J, McAdams HP. Pulmonary venous infarction after radiofrequency ablation for atrial fibrillation. AJR Am J Roentgenol 2002; 178: 664-666.

49 Reid J, Jamieson M, Cowan M. Unilateral pulmonary vein stenosis. Br Heart J 1986; 55: 599-601.

50 Routsi C, Charitos C, Rontogianni D, et al. Unilateral pulmonary edema due to pulmonary venous obstruction from fibrosing mediastinitis. Int J Cardiol 2006; 108: 418-421.

51 Saad EB, Marrouche NF, Saad CP, et al. Pulmonary vein stenosis after catheter ablation of atrial fibrillation: emergence of a new clinical syndrome. Ann Intern Med 2003; 138: 634-638.

52 Spragg DD, Dalal D, Cheema A, et al. Complications of catheter ablation for atrial fibrillation: incidence and predictors. J Cardiovasc Electrophysiol 2008; 19: 627-631.

53 Sritippayawan S, Margetis M, MacLaughlin E, et al. Cor triatriatum: a cause of hemoptysis. Pediatr Pulmonol 2002; 34: 405-408.

54 Swischuk L, L’Heureux P. Unilateral pulmonary vein atresia. AJR Am J Roentgenol 1980; 135: 667-672.

55 van der Werf TS, Mannes G. Hew JM, et al. Improved gas exchange after pneumonectomy in an adult with incomplete pulmonary vein atresia. Thorax 1994; 49: 723-725.

56 Walsh A, Canny G, McMahon CJ, et al. Hemoptysis from bronchial varices associated with pulmonary vein stenosis: role of surgical repair. Pediatr Pulmonol 2013; 48: 838-840.

57 Wiebe S, Maclusky I, Manson D, et al. Hemoptysis: a rare cause can be related to a bronchial varix due to pulmonary venous obstruction. Pediatr Radiol 2003; 33: 884-886.

58 Yacoub M, Thompson V. Chronic idiopathic pulmonary hilar fibrosis. A clinicopathological entity. Thorax 1971; 26: $365-375$ 
Yang HM, Lai C, Patel J, et al. Irreversible intrapulmonary vascular changes after pulmonary vein stenosis complicating catheter ablation for atrial fibrillation. Cardiovasc Pathol 2007; 16: 51-55.

60 Haponik E, Fein A, Chin R. Managing life-threatening hemoptysis: has anything really changed? Chest 2000; 118: 1431-1435.

61 Bidwell J, Pachner R. Hemoptysis: diagnosis and management. Am Fam Physician 2005; 72: 1253-1260.

62 Garwood S, Strange C, Sahn S. Massive hemoptysis. In: Parrillo JE, Dellinger RP, eds. Critical Care Medicine: Principles of Diagnosis and Management in the Adult. 3rd Edn. St Louis, Mosby Elsevier, 2008.

63 Jeudy J, Khan AR, Mohammed TL, et al. ACR Appropriateness Criteria hemoptysis. J Thorac Imaging 2010; 25 : W67-W69.

64 Andersen PE. Imaging and interventional radiological treatment of hemoptysis. Acta Radiol 2006; 47: 780-792.

65 Sakr L, Dutau H. Massive hemoptysis: an update on the role of bronchoscopy in diagnosis and management. Respiration 2010; 80: 38-58.

66 McIlroy DR, Sesto AC, Buckland MR. Pulmonary vein thrombosis, lung transplantation, and intraoperative transoesophageal echocardiography. J Cardiothorac Vasc Anesth 2006; 20: 712-715.

67 Leibowitz DW, Smith CR, Michler RE, et al. Incidence of pulmonary vein complications after lung transplantation: a prospective transesophageal echocardiographic study. J Am Coll Cardiol 1994; 24: 671-675.

68 Kowalski M, Grimes M, Perez F, et al. Histopathologic characterization of chronic radiofrequency ablation lesions for pulmonary vein isolation. J Am Coll Cardiol 2012; 59: 930-938.

69 Taylor G, Kay N, Zheng X, et al. Pathological effects of extensive radiofrequency energy applications in the pulmonary veins in dogs. Circulation 2000; 101: 1736-1742.

70 Calkins H, Kuck KH, Cappato R, et al. 2012 HRS/EHRA/ECAS Expert Consensus Statement on Catheter and Surgical Ablation of Atrial Fibrillation: recommendations for patient selection, procedural techniques, patient management and follow-up, definitions, endpoints, and research trail design. Europace 2012; 14: 528-606.

71 Tekbas G, Gumus H, Onder H, et al. Evaluation of pulmonary vein variations and anomalies with 64 slice multi detector computed tomography. Wien Klin Wochenschr 2012; 124: 3-10.

72 Dillman J, Yarram S, Hernandez R. Imaging of pulmonary venous developmental anomalies. AJR Am J Roentgenol 2009; 192: 1272-1285.

73 Marom EM, Herndon JE, Kim YH, et al. Variations in pulmonary venous drainage to the left atrium: implications for radiofrequency ablation. Radiology 2004; 230: 824-829.

74 Snellen HA, van Ingen HC, Hoefsmit C. Patterns of anomalous pulmonary venous drainage. Circulation 1968; 38: 45-63.

75 Sugimoto S, Izumiyama O, Yamashita A, et al. Anatomy of inferior pulmonary vein should be clarified in lower lobectomy. Ann Thorac Surg 1998; 66: 1799-1800.

76 Yamada S, Suga A, Inoue Y, et al. Importance of preoperative assessment of pulmonary venous anomaly for safe video-assisted lobectomy. Interact Cardiovasc Thorac Surg 2010; 10: 851-854.

77 Heath D, Edwards J. Histological changes in the lung in diseases associated with pulmonary venous hypertension. Br J Dis Chest 1959; 53: 8-18.

78 Pietra G, Capron F, Stewart S, et al. Pathologic assessment of vasculopathies in pulmonary hypertension. J Am Coll Cardiol 2004; 43: Suppl. 12, 25S-32S.

79 Pietra G, Edwards W, Kay J, et al. Histopathology of primary pulmonary hypertension. A qualitative and quantitative study of pulmonary blood vessels from 58 patients in the National Heart, Lung, and Blood Institute, Primary Pulmonary Hypertension Registry. Circulation 1989; 80: 1198-1206.

80 Frazier A, Galvin J, Franks T, et al. From the archives of the AFIP: pulmonary vasculature: hypertension and infarction. Radiographics 2000; 20: 491-524.

81 Chazova I, Robbins I, Loyd J, et al. Venous and arterial changes in pulmonary veno-occlusive disease, mitral stenosis and fibrosing mediastinitis. Eur Respir J 2000; 15: 116-122.

82 Ohmichi M, Tagaki S, Nomura N, et al. Endobronchial changes in chronic pulmonary venous hypertension. Chest 1988; 94: 1127-1132.

83 Williamson W, Tronic B, Levitan N, et al. Pulmonary venous infarction. Chest 1992; 102: 937-940.

84 Nanthakumar K, Mountz J, Plumb JV, et al. Functional assessment of pulmonary vein stenosis using radionuclide ventilation/perfusion imaging. Chest 2004; 126: 645-651.

85 Mendelson D, Train J, Goldsmith S, et al. Ventilation-perfusion mismatch due to obstruction of pulmonary vein. J Nucl Med 1981; 22: 1062-1063.

86 Aghaji MC. Radionuclide evaluation of unilateral pulmonary vein stenosis. Correlation with chest roentgenogram and clinical profiles. J Nucl Med Allied Sci 1986; 30: 225-229.

87 Lepădat P, Burnea D, Stăncioiu G, et al. Modificari scintigrafice si electrocardiografice dupa ligature la clini a arterei pulmonare, a venelar pulmonare si mixta [Scintigraphic and electrocardiographic changes after ligation of the pulmonary artery, pulmonary veins and mixed ligation in dogs]. Rev Chir Oncol Radiol ORL Oftalmol Stomatol Chir 1977; 26: 207-215.

88 Kluge A, Dill T, Ekinci O, et al. Decreased pulmonary perfusion in pulmonary vein stenosis after radiofrequency ablation: assessment with dynamic magnetic resonance perfusion imaging. Chest 2004; 126: 428-437.

89 Roman K, Kellenberger C, Macgowan C, et al. How is pulmonary arterial blood flow affected by pulmonary venous obstruction in children? A phase-contrast magnetic resonance study. Pediatr Radiol 2005; 35: 580-586.

90 Wyatt J, Burke D, Hanlon R. Morphological study of canine lungs after ligation of the pulmonary veins. Am J Pathol 1953; 29: 291-303.

91 Cavaco R, Kaul S, Chapman T, et al. Idiopathic pulmonary fibrosis associated with pulmonary vein thrombosis: a case report. Cases J 2009; 2: 9156.

92 Sacco O, Fregonese B, Fregonese L, et al. Recurrent unilateral bacterial pneumonias and interstitial fibrosis associated with pulmonary vein atresia: successful treatment with endovascular stent implantation. Pediatr Pulmonol 2002; 34: 324-328.

93 Palazzini M, Manes A. Pulmonary veno-occlusive disease misdiagnosed as idiopathic pulmonary arterial hypertension. Eur Respir Rev 2009; 18: 177-180.

94 Abikhzer G, Zand K, Stern J, et al. False positive high probability V/Q scan due to malignant obstruction of both pulmonary vein and artery. Clin Nucl Med 2009; 34: 367-370. 
95 Bailey C, Channick R, Auger W, et al. "High probability" perfusion lung scans in pulmonary venoocclusive disease. Am J Respir Crit Care Med 2000; 162: 1974-1978.

96 Wood M, Wittkamp M, Henry D, et al. A comparison of pulmonary vein ostial anatomy by computerized tomography, echocardiography, and venography in patients with atrial fibrillation having radiofrequency catheter ablation. Am J Cardiol 2004; 93: 49-53.

97 Roman K, Kellenberger C, Farooq S, et al. Comparative imaging of differential pulmonary blood flow in patients with congenital heart disease: magnetic resonance imaging versus lung perfusion scintigraphy. Pediatr Radiol 2005; 35: 295-301.

98 Valsangiacomo E, Barrea C, Macgowan C, et al. Phase-contrast MR assessment of pulmonary venous blood flow in children with surgically repaired pulmonary veins. Pediatr Radiol 2003; 33: 607-613.

99 Valverde I, Miller O, Beerbaum P, et al. Imaging of pulmonary vein stenosis using multidimensional phase contrast magnetic resonance imaging (4-dimensional flow). J Am Coll Cardiol 2011; 58: e3.

100 Greil G, Powell A, Gildein H, et al. Gadolinium-enhanced threee-dimensional magnetic resonance angiography of pulmonary and systemic venous anomalies. J Am Coll Cardiol 2002; 39: 335-341

101 Grosse-Wortmann L, Al-Otay A, Goo HW, et al. Anatomical and functional evaluation of pulmonary veins in children by magnetic resonance imaging. J Am Coll Cardiol 2007; 49: 993-1002.

102 Stanford W, Breen J. CT evaluation of left atrial pulmonary venous anatomy. Int J Cardiovasc Imaging 2005; 21: 133-139.

103 Burgstahler C, Trabold T, Kuettner A, et al. Visualization of pulmonary vein stenosis after radio frequency ablation using multi-slice computed tomography: initial clinical experience in 33 patients. Int J Cardiol 2005; 102: 287-291.

104 Kim Y, Marom E, Herndon J, et al. Pulmonary vein diameter, cross-sectional area, and shape: CT analysis. Radiology 2005; 235: 43-49.

105 Cronin P, Kelly AM, Desjardins B, et al. Normative analysis of pulmonary vein drainage patterns on multidetector CT with measurements of pulmonary vein ostial diameter and distance to first bifurcation. Acad Radiol 2007; 14: 178-188.

106 Hauser T, Yeon S, Kissinger K, et al. Variation in pulmonary vein size during the cardiac cycle: implications for non-electrocardiogram-gated imaging. Am Heart J 2006; 152: 974.

107 Thai W, Wai B, Lin K, et al. Pulmonary venous anatomy imaging with low-dose, prospectively ECG-triggered, high-pitch 128-slice dual-source computed tomography. Circ Arrhythm Electrophysiol 2012; 5: 521-530.

108 de Marchi S, Bodenmüller M, Lai D, et al. Pulmonary venous flow velocity patterns in 404 individuals without cardiovascular disease. Heart 2001; 85: 23-29.

109 Devaney E, Chang A, Ohye R, et al. Management of congenital and acquired pulmonary vein stenosis. Ann Thorac Surg 2006; 81: 992-995.

110 De Potter TJ, Schmidt B, Chun KR, et al. Drug-eluting stents for the treatment of pulmonary vein stenosis after atrial fibrillation ablation. Europace 2011; 13: 57-61. 